\title{
The Development and Rasch Calibration of a Scale to Measure Coordinative Motor Skills in Typically Developing Children
}

\author{
Giulia Bardaglio $^{1 *}$, Michele Settanni ${ }^{2}$, Danilo Marasso ${ }^{1}$, Giovanni Musella ${ }^{1}$, \\ Silvia Ciairano ${ }^{1,2}$ \\ ${ }^{1}$ Motor Science Research Center, University School of Motor \& Sport Sciences, \\ University of Torino, Torino, Italy \\ ${ }^{2}$ Department of Psychology, University of Torino, Torino, Italy \\ Email: "giulia.bardaglio@unito.it
}

Received April 17 $7^{\text {th }}, 2012$; revised May $15^{\text {th }}, 2012$; accepted May $30^{\text {th }}, 2012$

\begin{abstract}
The purposes of this study were to propose and calibrate an instrument based on systematic observation intended to measure coordinative motor skills in typically developing children. The instrument, called the Coordinative Motor Skills Scale (CMSS), was administered to 96 third grade children $(50 \%$ females, mean age $=8.4, S D=0.4$ ) from primary schools in northwest Italy. Data were analyzed employing the base Rasch model for dichotomous items (Rasch, 1960/1980). The Rasch analysis showed that the measure of coordinative motor skills is unidimensional and that the instrument was correctly targeted to the level of ability of the participants. Overall, CMSS was demonstrated to be suitable for assessing coordinative motor skills in normally developing children.
\end{abstract}

Keywords: Childhood; Movement Coordination; Rasch Model

\section{Introduction}

Movement coordination as expressed in coordinative motor skills can be defined as the ability to perform complex exercises accurately and quickly, with in constantly changing conditions (Starosta, 1989). Furthermore, we know that movement coordination and coordinative motor skills are the external manifesttation of functions of the central nervous system and that they should be measured at the proper time during individual development (Starosta, 2000). Coordinative abilities contribute to the resolution of movement tasks in a rational and creative way in the various fields of sport and daily life (e.g. climbing stairs, grasping objects, walking, jumping; Weineck, 2009).

Accordingly to Blume (1981), there are seven coordinative abilities: motor differentiation, motor connection, balance preservation, spatial orientation, motor rhythmization, speed reaction, and motor transformation. All these coordinative abilities occur in three structurally different sets: motor learning, motor control, and motor adaptation. The motor learning ability is connected with all the other coordinative abilities; the motor control ability is particularly connected with the ability to perform and regulate standard movements; finally, the motor adaptation ability is connected with abilities enabling movement adjustments to changing conditions and situations.

The optimal age for learning motor skills, including the coordinative ones, is difficult to define. However, late childhood, between the ages of 7 and 11 years, seems to be a "sensitive period" for the sequential development of gross motor skills (Gallahue, 1982), and particularly of movement coordination (Hirtz \& Starosta, 2002). Late childhood also corresponds to the third stage of Piaget's theory on cognitive development (1964):

\footnotetext{
*Corresponding author.
}

that of concrete mental operations. At this stage, children can understand and respect the rules of a team game and cooperate with peers in order to apply these rules to ensure the efficacy of the game (Gallahue).

Although the development of motor skills, including coordinative ones, is important in typically developing children, motor skills are often considered only when there are dysfunctions or inefficient movement behaviours present. Many studies focus on fundamental movement skills, but in most cases the instruments used are only able to detect deficiencies in the development of movement skills (Hartman, Houwen, Scherder, \& Visscher, 2010; Wuang, Lin, \& Su, 2009). Among others, the Movement Assessment Battery for Children (M-ABC; Henderson \& Sugden, 1992) and the Test of Gross Motor Development, Second Edition (TGMD-2; Ulrich, 2000), are two of the most commonly used tools for assessing movement skills, especially in clinical samples of children with developmental coordination disorders, in order to monitor children's motor coordination (Hartman et al., 2010; Hung \& Pang, 2010). Slater, Hillier and Civetta (2010) recommended the use of the M-ABC test and the TGMD-2 test for assessing developmental coordination disorders and gross motor performance in children. Vuijk, Hartman, Scherder and Visscher (2010) recently used the M-ABC test for comparing the motor skills of children with intellectual disabilities (ID) and of normally developing children. This study found that children with ID had significantly more borderline and definite motor problems than the normative sample, and there was an association between the degree of ID and the performance of manual dexterity, ball skills and balance skills.

The results of this study support the notion that levels of motor and cognitive functioning are related in children with ID. Finally, Staples and Reid (2010) used the TGMD-2 test for 
comparing the fundamental movement skills of children with autism spectrum disorders, aged 9 to 12 years, with same age groups of typically developing children.

We think that investigating the development of coordinative motor skills also deserves further attention in typically developing children and particularly when they use these skills in ecological kinds of tasks, such as team games. In fact the findings collected about these children and within these situations give us further information about which one of their components could be more efficient to train in order to obtain both an optimal development of motor skills and also even for recovery in temporary conditions of physical impairment.

Furthermore, the validity of the most common instruments for assessing the motor coordination of children seems still far from proven. In most cases, the various authors inform us about convergent and divergent validity but they do not provide plain statistic information for an accurate interpretation of the findings (Brown \& Lalor, 2009; Evaggelinou, Tsigilis, \& Papa, 2002; Van Waelvelde, Peersman, Lenoir, \& Engelsman, 2007). Brown and Lalor individuated one major weakness of the Movement Assessment Battery for Children, Second Edition (MABC-2) in its lack of evidence of construct validity and they suggest further analysis with the Rasch Measurement Model. With respect to the Test of Gross Motor Development (TGMD), Ulrich (1985) presents the findings of a principal components analysis that showed three components and four items with high loadings on two different components. Nevertheless, Ulrich referred to only one component, and this interpretation was confirmed by Zhu and Cole (1996). However, the study by Evaggelinou et al. found that seven items loaded on one factor (i.e., children's locomotion skills - their ability to move within a space) and five items overloaded another factor (i.e., object control skills). Lee, Zhu, and Ulrich (2005) confirmed the unidimensionality and the psychometric properties of the TGMD-2 test using a calibration method based on the Many-Facet Rasch Model.

In sum, there are some indications that we still lack reliable information on the development of coordinative motor skills in typically developing children, and also that the Rasch calibretion model (Rasch, 1960/1980) is the most appropriate statistic technique that can validate the instruments for assessing movement development and performance in children (Chien \& Bond, 2009; Wuang et al., 2009). The Rasch model is a unidimensional scaling based on the relation between the subject's ability and item difficulty, and it can overcome the limitations of traditional approaches based on the Classical Test Theory (CTT). Rasch modeling has been successfully used for estimating abilities, attitudes, and personality traits in psychological and educational research. The Rasch model uses a model-based approach that permits the developing of scales with strong measurement properties, in particular with regards to generalizability, accuracy and statistical validity (Embretson \& Reise, 2000). One of the advantages of Rasch modelling is that it allows for independently scaling items and persons along a continuous interval-scaled latent trait (Bond \& Fox, 2007; Rasch, 1960/1980). As a consequence, when data show a good fit to the Rasch model the latent trait will be measured on a true interval scale (Bond \& Fox), hence obtained measures are eligible for analysis using statistical techniques that assume the data are measured at intervals (e.g., regression or ANOVA). Another big advantage of the Rasch model over the CTT is that it permits the analysis of the measurement invariance of the tested instruments in different groups by means of Differential Item Functioning (DIF) statistics. DIF analysis permits the study of the functioning of each item belonging to the instrument and to recognize possibly misbehaving items that could led to biases in the measurement (Myers, Wolfe, Feltz, \& Penfield, 2006).

The purpose of this study is to generate and calibrate a scale to measure coordinative motor skills (Coordinative Motor Skills Scale, CMSS) in a group of typically developing children using the Rasch model and to further validate the scale through the convergent, divergent, and know-difference validity approach. In particular we concentrated on a specific team game called Dodgeball because it is a non specialised team game frequently used when teaching various team games. It shares some basic characteristics of other team games, such as a high level of cooperation between players, the in-motion regulatory condition of the environment, the intertrial variability between different repetitions of the same skill, and the use of objects (Gentile, 2000).

With respect to convergent and divergent validity, we expected that our instrument would be related to one of the sub-scales of the TGMD, and the control object (TGMD) can precisely be considered one component of the more general construct of coordinative motor skills (Lombardozzi, Musella, Balducci, \& Barigelli, 2001). Yet, we did not expect that the CMSS would be linked with the other subscales of the TGMD - namely, the locomotion subscale-because locomotion is a major basic motor pattern that normally is already consolidated during the first cycle of primary school (Ulrich, 1985).

Finally, in order to evaluate the construct validity of the new scale by the know-difference validity approach we expected that our instrument would be able to discriminate between the levels of coordinative motor skills in children who are usually involved in scarce (fixed at less than two hours weekly) or frequent (fixed at two hours or more weekly) physical activity. The discrimination between scarce or frequent physical activity was fixed at two hours per week on the basis of the National Italian Guidelines on Education (2007) and of other previous studies (e.g., Klepp, Tell Grethe, \& Vellar Odd, 1994). Using this cut-off we assigned children to the "scarce physical activity" group (less than two hours weekly) or to the "frequent physical activity" group (two or more hours weekly).

\section{Methods}

\section{Inventory Development}

Systematic observation tries to reduce the excessive subjecttivity of general observation, making it an excellent qualitative tool for educational research and the evaluation of behaviour. In fact the coordinative motor skills that typically developing children usually use in team games are difficult or impossible to measure through the quantitative and validated tests present in the literature. Besides this, the level of the subjectivity of systematic observation can be limited through the use of clear and simple descriptors of the learning motor activity to be observed. In this way, the observed situation is broken down into criteria (namely descriptors) that are the components of the complex situation. These descriptors are then filled into a checklist and can be evaluated with a dichotomous scale, signalling the presence or the absence of the descriptor (Aureli, 1997).

Thus, the Coordinative Motor Skills Scale (CMSS) is a systematic observation tool. The outcome of this observation is a measure of coordinative motor skills. In particular, we chose the coordinative motor skills observed in a specific situation- 
namely, during a simple team game with a ball (Dodgeball). Even if there are various differences between team games, the five most common motor skills of these types of games are passing the ball, shooting the ball, movement with the ball, movement without the ball in attack and movement without the ball in defence (Lombardozzi et al., 2001). We chose the game of Dodgeball because it is a popular game in Italy and it is frequently used during normal classes of physical activity in primary school. The popularity of this game and the moderate physical effort that it requires allows boys and girls to play it together without any difference. In addition we have not used a codified sport because the choice of a codified sport would not have matched the aims of physical education in Italian primary school, which are only to increase coordinative motor skills and are not focused on one specific sport. Specific aspects of sport are introduced only in the last two years of primary school, which is not an age group we considered in this study. Finally, we did not choose a codified sport because we would have favored children who also practice this sport outside school and gender differences also could have arisen. In fact, among people who practice sports in Italy, $41 \%$ of males practice football compared to $1.4 \%$ of females. On the contrary, $3.3 \%$ of males practice volleyball compared to $10 \%$ of females (ISTAT, 2005).

The CMSS was previously tested in one pilot research project (Marasso, 2009) that belongs to a huge longitudinal project called "Educatamente Sport", which is still in progress. In this pilot study the systematic observation tool consisted of ten items obtained by combining the five most common motor skills of team games with motor control ability and motor adaptation ability (Blume, 1981). The ten items observed are the pass-motor control ability, pass-motor adaptation ability, shooting-motor control ability, shooting-motor adaptation ability, movement with the ball-motor control ability, movement with the ball-adaptation ability, attack-motor control ability, attack-motor adaptation ability, defence-motor control ability, and defence-motor adaptation ability. The exploratory factor analysis indicated that the two items about movement with the ball (motor control ability and adaptation ability) did not fit with the scale, probably due to the excessive difficulty in their evaluation $(\alpha=.50$ if both are included). For this reason, these two items were deleted to improve the reliability of the scale $(\alpha=.72)$.

The CMSS consists of eight items. The eight items observed are: pass-motor control ability, pass-motor adaptation ability, shooting-motor control ability, shooting-motor adaptation ability, attack-motor control ability, attack-motor adaptation ability, defence-motor control ability, and defence-motor adaptation ability. The descriptors of these eight items are illustrated in Table $\mathbf{1 .}$ These items are reported in a checklist and are evaluated using a dichotomous item, reporting the presence or the absence of each descriptor. Ultimately, the entire set of eight items may belong to a higher-order factor structure, evaluated with values between zero to eight, which expresses a unidimensional concept of coordinative motor skills in team games.

\section{Participants}

The data used in this study were collected from 96 children who attended third-grade classes of primary schools in northwest Italy. The sample was balanced for gender (50\% females); the mean age of the participants was 8.4 years $(S D=0.4)$ and the main socio-demographic information of the participants is similar to that found in the general Italian population (ISTAT, 2010).

\section{Procedure}

Our research was approved by the Ethical Committee of the University of Torino. We collected all the required informed consent from the parents of the children (because the children are minors) according to the ethical principles for research of the Italian Psychological Association. We also collected active consent from the children themselves.

The study was conducted in four public primary schools and from each school we randomly selected 24 children. These children brought a questionnaire home to their parents who completed the questionnaire about their socio-demographic information and the children's number of hours spent practicing sports or motor extra-curricular activities. The questionnaire was completed by $58 \%$ of the mothers, $14 \%$ of the fathers, and $28 \%$ by both parents. This questionnaire took approximately 15 minutes to complete.

Data about motor skills were collected in a gymnasium. The administration of both tests - the TGMD test (Ulrich, 1985) and the CMSS check-list - required approximately four hours for all the children from one school. The observation protocol included a camera and the simultaneous presence of three observers, all doctoral students, who were experts in physical education and participated in a specific observer training; each observer was equipped with two checklists (the TGMD and CMSS tests).

In reference to the CMSS test, the presence or absence of the descriptors must be reported on the checklist during the observation of a team game (Dodgeball). For coding purposes, the

Table 1.

Descriptors of 8 items of the Coordinative Motor Skills Scale (CMSS).

\begin{tabular}{|c|c|}
\hline Items & Descriptors \\
\hline 1. Pass-motor control ability & $\begin{array}{l}\text { He/she throws the ball, regulating the action, with force and trajectory to assume that the ball arrives in the hands } \\
\text { of the teammate. }\end{array}$ \\
\hline 2. Pass-motor adaptation ability & $\begin{array}{l}\mathrm{He} / \text { she chooses to pass the ball to the teammate closest to the half way line in reference to the field layout of the } \\
\text { opponents. }\end{array}$ \\
\hline 3. Shooting-motor control ability & $\mathrm{He} /$ she throws the ball, regulating the gesture, with force and trajectory to assume the success of the shooting. \\
\hline 4. Shooting-motor adaptation ability & $\begin{array}{l}\mathrm{He} / \mathrm{she} \text { chooses to hit with the ball the opponent closest to the half way line in reference to the field layout of the } \\
\text { others opponents. }\end{array}$ \\
\hline 5. Attack-motor control ability & $\begin{array}{l}\mathrm{He} / \text { she moves and positions to receive the ball and attack, always keeping eye contact with teammate in possession } \\
\text { of the ball. }\end{array}$ \\
\hline 6. Attack-motor adaptation ability & $\begin{array}{l}\text { He/she chooses to move, in the position closest to the half way line in reference to the field layout of the opponents, } \\
\text { in order to receive the ball and attack. }\end{array}$ \\
\hline 7. Defence-motor control ability & $\begin{array}{l}\mathrm{He} / \text { she is positioned to receive the ball from opponents always keeping the front facing the opponent in possession of } \\
\text { the ball. }\end{array}$ \\
\hline 8. Defence-motor adaptation ability & $\begin{array}{l}\text { He/she chooses the defensive position farther than the half way line in reference to the opponent in possession of the } \\
\text { ball that is attacking. }\end{array}$ \\
\hline
\end{tabular}


playing time was divided into game actions. Each game action involved the evaluation of all the items. The analysis of the prevalence of dichotomous values for each descriptor in each action give the final dichotomous value for each item. The game situation was observed by all of the researchers at the same time and each session of play was immediately coded independently by the three observers. The proportion of agreement between the scores assigned by the different coders was considered very high because it was about 95\% (D'Odorico, 1990). Furthermore, the few disagreements were immediately resolved with the external contribution of a fourth researcher not directly involved in the observation session. In the case of a disagreement, the coders were invited to justify their choices and, after a short discussion, in all cases they came to an agreement (D'Odorico).

The game comprised of six children divided into two teams, three versus three.

The criterion for composing the teams was random. Before the start of the game, there was a clear and precise explanation of the rules of Dodgeball to the children. This period was aimed at giving children the same explanations and rules even if all the children already knew the game. Finally, the three doctoral students observed 6 children at a time (3 vs. 3) for approximately 20 minutes during the game time period. This required approximately 80 minutes (4 team game periods, each 20 minutes long) to observe and register the behaviour of all the 24 children from one school with respect to the CMSS scale.

\section{Data Analysis}

\section{Preliminary Analysis}

Before proceeding with the further steps of the analysis, to evaluate the possibility of school biases we used the one-way analyses of variance (ANOVA) and the Tukey Post-Hoc test to analyze the differences between different school settings on the results of the CMSS test. The absence of significant differences between classes permitted us to exclude the influences of different school settings.

\section{Model-Data Fit}

The data were analyzed using Winsteps software (Linacre, 2005) employing the base Rasch model for dichotomous items (Rasch, 1960/1980). According to the Rasch model, the probability of an answer when a person faces an item can be described as a function of the person's position on the latent trait (here, coordinative motor skills in team games). Given the answers of $n$ persons to $k$ items built to measure the same latent trait, such person and item parameters can be statistically estimated. These estimates represent a person's ability and the measures of item difficulty and are expressed in units called logits. The software we used conventionally defines the mean of the item measures as zero. With regard to the main fit statistics reported here, the infit "is an information weighted fit statistic, which is more sensitive to unexpected behavior affecting responses to items near the person's measure level"; the outfit "is an outlier-sensitive fit statistic, more sensitive to unexpected behavior by persons on items far from the person's measure level"(Linacre). Infit and outfit values substantially less than 1.0 suggest an overfit that may lead to inflated statistics, whereas values in excess of 1.0 indicate unmodeled noise (underfit). In accordance with the literature (Wright \& Linacre, 1994), acceptable ranges of infit and outfit values are between 0.5 and 1.5.

\section{Item Location and Person Measures}

The logit unit is the natural logarithm of the odds of a person being able to perform a particular task or an item being successfully carried out. Regarding the CMSS items, higher difficulty measures correspond to the higher level of coordinative ability needed to perform the task. A comparison of the mean location score obtained for persons (average ability) with that of the value of the zero set for the items allows for the evaluation of the targeting of the items to the sample (i.e., how well the CMSS measures the sample under study). A mean person measure close to zero would represent the ideal targeting of the items in terms of their difficulty for the sample. A mean person measure much higher or lower than zero would indicate that the item set is mistargeted with respect to the sample (Bond \& Fox, 2007).

\section{Differential Item Functioning}

Gender-based item invariance was studied by considering the differential item functioning (DIF) of each item. A DIF item is one for which there is a different likelihood of endorsement for members of different subgroups. In regard to the CMSS items, we expected the difficulty of the items to be the same for both males and females. Ascertaining the absence of items with a significant DIF allows for affirming that the differences in coordinative abilities in team games found between males and females are based on real differences and not on items that perform in a different way across the two subsamples. The DIF may be verified by statistically testing dif ferences in estimated item parameters (paired t-tests).

\section{Convergent Validity, Divergent Validity, and Know-Difference Validity Evidence}

In order to further evaluate the validity of the instrument, convergent, divergent, and know-difference validity were also assessed. With regard to convergent and divergent validity, bivariate correlations were computed between CMSS scores and TGMD subscales. In order to further evaluate the construct validity, a one-way ANOVA was conducted to test the presence of differences in the levels of coordinative motor skills among groups with a different number of hours spent practicing sports or motor extra-curricular activities.

\section{Results}

\section{Model-Data Fit}

On the whole, the CMSS data fitted the Rasch model well. Infit and outfit statistics (as reported in Table 2) are maintained between the recommended thresholds ( 0.5 and 1.5$)$; hence, they provide evidence supporting the substantial unidimensionality of the construct that was measured. The absence of both underfitting and overfitting items indicates that all the considered tasks were adequate to measure the construct and there was no need to remove or modify the items.

\section{Item Location and Person Measures}

Figure 1 shows the distribution along the same continuum of the measures of both participant abilities and item difficulties. The measure unit is the logit; point zero corresponds to the mean item difficulty level. The map clearly shows that the distribution of item difficulties $(M=.00, S D=1.75)$ is quite well 
Table 2.

Summary of the CMSS items.

\begin{tabular}{lccccc}
\hline & Measure (logit) & SE & \% of correct performance & Infit & Outfit \\
\hline Attack-motor adaptation ability & 2.00 & 0.31 & 28 & 0.78 & 0.45 \\
Defense-motor adaptation ability & 1.91 & 0.3 & 29 & 34 & 1.13 \\
Attack-motor control ability & 1.47 & 0.29 & 49 & 0.8 & 0.73 \\
Defense-motor control ability & 0.34 & 0.27 & 55 & 1.26 & 0.58 \\
Shooting-motor control ability & -0.08 & 0.26 & 76 & 1.22 & 1.36 \\
Pass-motor adaptation ability & -1.53 & 0.27 & 76 & 0.98 & 1.29 \\
Pass-motor control ability & -1.53 & 0.27 & 88 & 0.91 & 1.22 \\
Shooting-motor adaptation ability & -2.59 & 0.33 & & & 0.62 \\
\hline
\end{tabular}

Shooting-motor adaptation ability

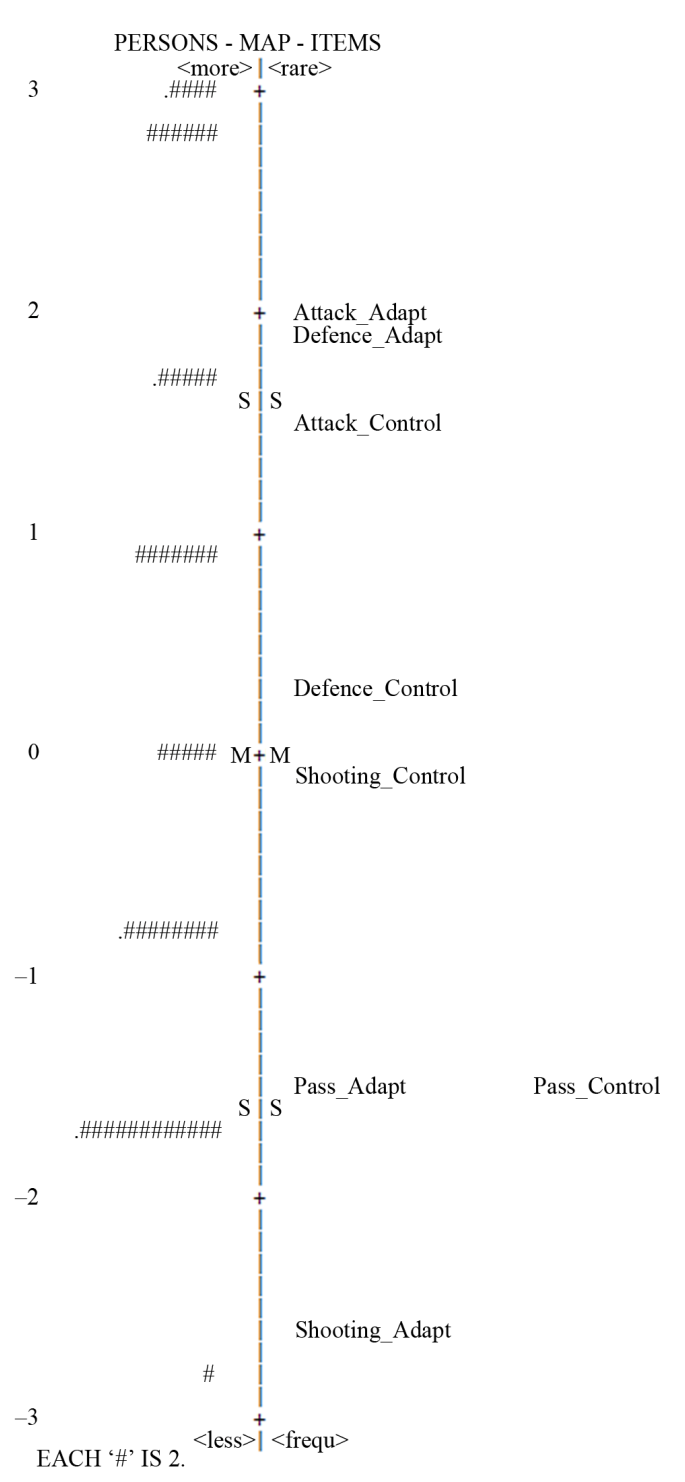

Figure 1.

Items and subject measures map.

targeted with respect to the distribution of person abilities ( $M$ $=.40, S D=1.93$ ). Item and student measures were widely distributed along the logit continuum. Table 2 shows the CMSS item difficulties (expressed in logits) with standard errors, the percentage of students who correctly performed each task, and infit and outfit statistics. Results of the Rasch calibration indicated that item difficulties ranged between -2.59 and 2.00 logits, with higher scores corresponding to more difficult items. The most difficult task was the attack-motor adaptation ability (correctly performed by $28 \%$ of the students), while the least difficult task was the shooting-motor adaptation ability (correctly performed by $88 \%$ of the students). The ability measures of the students ranged between 4.18 and -2.82 logits.

\section{Differential Item Functioning}

Gender-based item invariance was studied by considering the DIF of each item with respect to gender. The DIF contrasts, computed as the differences between difficulty measures separately obtained for males and females, ranged between .16 and .91 and were always non-significant. This result indicates that the items worked in the same way for both genders.

\section{Convergent Validity, Divergent Validity, and Know-Difference Validity Evidence}

The CMSS and the TGMD measures (Ulrich, 1985) used in this study were compared to establish validity evidence. A positive relationship $(r=0.39, p<.001)$ exists between the two measures. These measures obtained with the new instrument (i.e., CMSS) correlated in a very different way with the two TGMD subscales. Indeed, the TGMD object control subscale showed a stronger correlation $(r=.43, p<.001)$ with the CMSS. Instead, the TGMD locomotion subscale did not show a significant correlation with the CMSS $(r=.14, p=.138)$. These results support the convergent and divergent validity of the CMSS. In order to further test the construct validity of the instrument, the sample was split into two groups according to the number of hours spent practicing sport or motor extra-curricular activity ( 0 - 2 hours and more than 2 hours), and a one-way ANOVA was conducted to test the differences in coordinative abilities, i.e. in the CMSS scores, between the two groups (see Table 3). Children who spent more than two hours practicing sports or extra-curricular motor activity obtained significantly higher scores than children who spent less than two hours in the same kind of activities: $F(1,98)=3.89, p<.05, \eta^{2}=.039$.

\section{Discussion and Conclusion}

The purposes of this study were to generate and calibrate a unidimensional CMSS for typically developing children using the Rasch model and to further validate the scale through the convergent, divergent, and know-difference validity approach. The substantial validity of the CMSS was confirmed through the various steps of the research. The first step of this study was devoted to the generation of the new instrument. In the second step the new instrument was calibrated using the Rasch model, which showed a good level of targeting with the level of the 
Table 3.

Know-difference validity evidence.

\begin{tabular}{ccccc}
\hline \multicolumn{5}{c}{ CMSS } \\
\hline No of hours & $N$ & $M$ & $S D$ & ANOVA \\
\hline $0-2$ & 37 & -.90 & 1.71 & $F(1.98)=3.89$ \\
More than 2 & 63 & .70 & 2.01 & $p<.05 \eta^{2}=.04$ \\
\hline
\end{tabular}

participants' ability. Furthermore, the unidimensionality of the instrument was verified using the Rasch model. Finally, the test of convergent validity, divergent validity, and know-difference validity were all satisfactory.

Referring to convergent validity, the results are in accordance with theoretical expectations. In fact, we found a positive correlation between the CMSS and the TGMD object control sub-scale. This finding is justified by the fact that the specific skills for controlling objects are included in the general construct of coordinative motor skills in team games. In particular, one of the most important peculiarities of game activitiesespecially team games-is the use of an object, usually a ball (Lombardozzi et al., 2001).

Regarding the divergent validity, as expected the TGMD locomotion subscale was not correlated with the CMSS. In fact, our participants are children from the second cycle of primary school, while the major basic motor patterns (like locomotion) are usually already consolidated during the first cycle of primary school (Ulrich, 1985). Furthermore, this finding suggests that locomotion skills may be not included in coordinative motor skills in the team games of typically developing children.

Finally, as expected, the CMSS was able to discriminate between different quantities of motor practice (i.e., known-difference validity). Children who spent more than two hours per week on motor activities (curricular, extra-curricular, physical activity in leisure time) obtained significantly higher scores than children who spent less than two hours practicing motor activities. Indeed, we expected that extensive physical activity would improve the coordinative motor skills in children between 7 and 11 years, because at this age the high plasticity of the cerebral cortex provides the opportunity to significantly develop coordinative motor skills (Weineck, 2009).

Although our results are encouraging, this study also has several limitations. First, the relatively small sample size and the fact that all the participants live in one region of Italy makes it difficult to generalize results to different populations. A largerscale investigation is recommended. Second, the limited number of dimensions considered and the absence of control for other parameters (i.e., physical, social, psychological) do not allow for a complete explanation of a phenomenon as complex as human movement. Third, further studies are necessary to refine the scale and improve all kinds of validities. In addition, test re-test reliability is recommended.

Despite all its limitations, the CMSS seems to be a valid instrument to assess coordinative motor skills in team games of typically developing children. The results of calibration, convergent, divergent, and know-difference validity encourage continued research in this direction. Unlike many instruments, which appear more suitable for detecting deficiencies in movement skills development (Hartman et al., 2010; Wuang et al., 2009), our new instrument (CMSS) can be used for investigating coordinative motor skills in the team games of typically developing children. As has been reported, we think that investigating the development of coordinative motor skills also deserves fur- ther attention in typically developing children and particularly when these skills are used in ecological kinds of tasks, such as team games.

\section{Acknowledgements}

The authors acknowledge CRC Foundation of Cuneo, CRT Foundation and ISEF Foundation of Torino, Italy, for contrib.uting to this study.

\section{REFERENCES}

Aureli, T. (1997). L'osservazione del comportamento del bambino (The observation of the child's behavior). Bologna, IT: Il Mulino.

Blume, D. D. (1981). Kennzeichnung Koordinativer Fähigkeiten und Möglichkeiten ihrer Herausbildung im Trainingprozess. In W. Starosta (Ed.), The importance of movement co-ordination, its structure and the hierarchy of integrant elements in sport and physical education (pp. 14-88). Roma: Centro Studi \& Ricerche, Federazione Italiana di Atletica Leggera.

Bond, T. G., \& Fox, C. M. (2007). Applying the Rasch model: Fundamental measurement in the human sciences ( $2^{\text {nd }}$ ed.). London: Lawrence Erlbaum.

Brown, T., \& Lalor, A. (2009). The movement assessment battery for children-second edition (MABC-2): A review and critique. Physical \& Occupational Therapy in Pediatrics, 29, 86-103. doi: $10.1080 / 01942630802574908$

Chien, C. W., \& Bond, T. G. (2009). Measurement properties of fine motor scale of Peabody developmental motor scales-second edition: A Rasch analysis. American Journal of Physical Medicine \& Rehabilitation, 88, 376-386. doi:10.1097/PHM.0b013e318198a7c9

D'Odorico, L. (1990). L'osservazione del comportamento infantile (The observation of child behavior). Milano, IT: Cortina.

Embretson, S. E., \& Reise, S. P. (2000). Item response theory for psychologists. Mahwah, NJ: Erlbaum.

Evaggelinou, C., Tsigilis, N., \& Papa, A. (2002). Construct validity of the test of gross motor development: A cross-validation approach. Adapted Physical Activity Quarterly, 19, 483-495.

Gallahue, D. L. (1982). Understanding motor development in children. New York: John Wiley \& Sons.

Gentile, A. M. (2000). Skill acquisition: Action, movement, and neuromotor processes. In J. H. Carr, \& R. D. Shepherd (Eds.), Movement science: Foundations for physical therapy ( $2^{\text {nd }}$ ed., pp. 111-187). Rockville, MD: Aspen.

Hartman, E., Houwen, S., Scherder, E., \& Visscher, C. (2010). On the relationship between motor performance and executive functioning in children with intellectual disabilities. Journal of Intellectual Disability Research, 54, 468-477. doi:10.1111/j.1365-2788.2010.01284.x

Henderson, S. E., \& Sugden, D. A. (1992). Movement assesment battery for children. Sidcup, Kent: Therapy Skill Builders.

Hirtz, P., \& Starosta, W. (2002). Sensitive and critical periods of motor co-ordination development and its relation to motor learning. Journal of Human Kinetics, 7, 19-28.

Hung, W. W., \& Pang, M. Y. (2010). Effects of group-based versus individual-based exercise training on motor performance in children with developmental coordination disorder: A randomized controlled study. Journal of Rehabilitation Medicine, 42, 122-128. doi: 10.2340/16501977-0496

ISTAT (2005). Lo sport che cambia. I comportamenti emergenti e le nuove tendenze della pratica sportiva in Italia. The sport is changing. The emerging behavior and new trends of sport in Italy. Roma, IT: ISTAT.

ISTAT (2010). Annuario statistico italiano 2010 (Italian statistical year book 2010). Roma, IT: ISTAT.

Klepp, K. I., Oygard, L., Tell Grethe, S., \& Vellar Odd, D. (1994). Twelve year follow-up of a school-based health education programme. European Journal of Public Health, 4, 195-200. doi:10.1093/eurpub/4.3.195

Lee, M., Zhu, W., \& Ulrich D. A. (2005). Many-faceted rasch calibration of TGMD-2. Research Quarterly for Exercise and Sport, 76, 116. 
Linacre, J. M. (2005). A user's guide to Winsteps/Ministeps Raschmodel programs. Chicago, IL: MESA Press.

Lombardozzi, A., Musella, G., Balducci, F., \& Barigelli, E. (2001). Giochi sportivi (Sports games). Padova, IT: Piccin Nuova Libraria S.p.a.

Marasso, D. (2009). La complessità della valutazione oggettiva nel gesto motorio (The complexity of the objective evaluation of the motor gesture). Torino, IT: Scuola Universitaria Interfacoltà In Scienze Motorie.

Myers, N. D., Wolfe, E. W., Feltz, D. L., \& Penfield, R. D. (2006). Identifying Differential Item Functioning of Rating Scale Items with the Rasch Model: An Introduction and an Application. Measurement in Physical Education and Exercise Science, 10, 215-240. doi:10.1207/s15327841mpee1004_1

National Italian Guidelines on Education (2007). Indicazioni per il curricolo-Per la scuola dell'infanzia e per il primo ciclo d'istruzione. Indications for the curriculum-For school children and for the first cycle of education. Roma, IT: Ministero della Pubblica Istruzione.

Piaget, J. (1964). Six études de psychologie (Six psychological studies). Paris: Folio Essays.

Rasch, G. (1960). Probabilistic model for some intelligence and achievement tests. Copenhagen: Danish Institute for Educational Research.

Rasch, G. (1980). Probabilistic model for some intelligence and achievement tests. Chicago, IL: University of Chicago Press.

Slater, L. M., Hillier, S. L., \& Civetta, L. R. (2010). The clinimetric properties of performance-based gross motor tests used for children with developmental coordination disorder: A systematic review. Pediatric Physical Therapy, 22, 170-179. doi:10.1097/PEP.0b013e3181dbeffo

Staples, K. L., \& Reid, G. (2010). Fundamental movement skills and autism spectrum disorders. Journal of Autism Development Disorder, 40, 209-217. doi:10.1007/s10803-009-0854-9

Starosta, W. (1989). Poziom koordynacji ruchowej u finalistów Ogól- nopolskiej spartakiady Mlodzieøy. In W. Starosta (Ed.), The importance of movement co-ordination, its structure and the hierarchy of integrant elements in sport and physical education (pp. 14-88). Roma: Centro Studi \& Ricerche, Federazione Italiana di Atletica Leggera.

Starosta, W. (2000). Osnowni koordinacionni sposobnosti, struktura i znaczenie za postizenieto $\mathrm{w}$ turnirnite sportni tanci. In W. Starosta (Ed.), The importance of movement co-ordination, its structure and the hierarchy of integrant elements in sport and physical education (pp. 14-88). Roma: Centro Studi \& Ricerche, Federazione Italiana di Atletica Leggera.

Ulrich, D. A. (1985). Test of gross motor development. Austin, TX: Pro-ED. Inc.

Ulrich, D.A. (2000). Test of gross motor development: Examiner's manual ( $2^{\text {nd }}$ ed). Austin, TX: Pro-ED. Inc.

Van Waelvelde, H., Peersman, W. Lenoir, M., \& Engelsman, B. C. (2007). Convergent validity between two motor tests: Movement-ABC and PDMS-2. Adapted Physical Activity Quarterly, 24, 59-69.

Vuijk, P. J., Hartman, E., Scherder, E., \& Visscher, C. (2010). Motor performance of children with mild intellectual disability and borderline intellectual functioning. Journal of Intellectual disability Research, 54, 955-965. doi:10.1111/j.1365-2788.2010.01318.x

Weineck, J. (2009). L'allenamento ottimale (The optimal training). Perugia, IT: Calzetti e Mariucci.

Wright, B. D., \& Linacre, J. M. (1994). Reasonable mean-square fit values. Rasch Measurement Transactions, 8, 370-371.

Wuang, Y. P., Lin, Y. H., \& Su, C.Y. (2009). Rasch analysis of the Bruininks-Oseretsky Test of Motor Proficiency-Second Edition in intellectual disabilities. Research in Developmental Disabilities, 30, 1132-1144. doi:10.1016/j.ridd.2009.03.003

Zhu, W., \& Cole, E. L., (1996). Many-faceted Rasch calibration of a gross motor instrument. Research Quarterly for Exercise and Sport, 67, 24-34. 